\title{
Integrated primary care may be the answer but do we really know what it is?
}

Developing more integrated care is now a key focus of health systems across the world although ideas of integrating health and social care services has been a topic of debate since the development of modern health and social care services. While not a new idea or development, there is increasing emphasis in many countries to accelerate such moves as health and social care systems struggle to meet changing demographic and epidemiological changes and the challenges of addressing increasing numbers of older people and people with chronic health problems and multi-morbidities. For example, in the United Kingdom, National Health Service England (2014) has recently set out an ambition to make the biggest national move to integrated care of any major western country. Integrated care comes in many forms depending on the structure of local health and care systems. However, as systems focus their attention on people with chronic health problems and multimorbidities, the role of primary health-care teams becomes increasingly important as an ingredient in the provision of integrated care. However, what the exact composition of teams should be to deliver the best patient outcomes is not clear and the evidence regarding the outcomes of effective primary health-care teams is sparse (Smith et al., 2016).

There is no universally agreed definition of what is meant by integrated care although it is generally seen as incorporating care co-ordination, case management, self-management support and care by multi-disciplinary clinical pathways and/or teams (Nolte and Pitchforth, 2014). The results from a Commonwealth Fund survey on care coordination suggests that countries with stronger primary care services where patients have an established relationship with a primary care physician was positively associated with better care co-ordination, although chronically ill and younger patients experienced poorer co-ordination (Penm et al., 2017). Care co-ordination across occupational and organisational boundaries is an important mediator of health-care outcomes for older people with multiple chronic co-morbidities

(C) Cambridge University Press 2017
(Nolte and Pitchforth, 2014). Approaches to building such inter-occupational and organisational models varies - ranging between single, co-located unified organisations to broad networks and federations of organisations. However, the evidence increasingly suggests that an integrated organisation containing a wide range of services including primary medical care, may be more likely to favour the development of care co-ordination, and therefore continuities of care, than co-ordination by care network (Sheaff et al., 2015).

Care for patients with complex health-care needs is typically coordinated through three types of interlocking networks: the patient's informal support network (family members, friends, volunteers, etc.); the staff or team(s) within each organisation providing care; and an inter-organisational 'referral network' with its pooled resources. Primary care services can play a key role within such networks providing key first point of contact support for patients and their families. Such a role involves more than the delivery of primary medical care and the evidence suggests that achieving good care co-ordination and continuity of care requires embracing primary care models built on the principles of Alma Ata. There is substantial interest in building different models of primary care and as in the United Kingdom, other countries are beginning to explore ideas of scaling up primary care (van den Hombergh and Campbell, 2013; Pineault et al., 2016). Existing studies document inherent weaknesses of the existing structure for the delivery of care including fragmentation, poor co-ordination between professionals, improved information sharing, greater organisational and management efficiencies, greater effectiveness and improved patient care (Thompson, 2011). There are many different models, funding structures and views about what constitutes the best way to organise primary care but generally more diverse professional and lay roles within primary care teams tend to provide better support than simply larger primary medical service models. 
Primary care services have long supported the involvement of nursing and other allied health professional staff but addressing how services support the increasingly complex needs of people living in the community requires building more diverse teams is becoming increasingly important. The beneficial role of community health workers, care navigators, social workers and advice workers is well supported by evidence (Landers and Levinson, 2016). However, how such services can be aligned with and integrated into primary care services is less well understood. In our rush to develop new models of care, we need to take note that previous research suggests that context matters in the development of primary care models and that there is no one way to develop a primary care model that will meet the needs of patients and providers across all contexts (van den Hombergh and Campbell, 2013; Pineault et al., 2016). Integrated models of care lack good research evidence to back them up, and it remains unclear what the important ingredients of a successful model might be. Clearly, integration requires greater reciprocal interdependence between professionals and other workers, patients and their families due to the complexity of the relationships and, necessitates a high level of co-ordination and collaboration. This sets a challenge for health systems in terms of the kinds of primary care practitioners we need for the future, and how we train them.

It is clear that primary care has a central role to play in developing integrated services if care co-ordination and continuity of care are to be maintained. How we design such services is more problematic. It seems that within each organisational model it is key micro-level team composition and functioning factors that are most important and there is a need for evidence on successful team working in multi-disciplinary primary care (Bramwell et al., 2015). Given there is no specific model for achieving successful integrated primary care we need well-designed evaluations of newly developing models of care together with the development of methods for assessing successful models of care if we are to ensure services meet people's complex needs.

$$
\begin{array}{r}
\text { Stephen Peckham } \\
\text { Director } \\
\text { Centre for Health Services Studies } \\
\text { University of Kent, Canterbury, Kent, UK }
\end{array}
$$

\section{References}

Bramwell, D., Peckham, S., Allen, P. and Checkland, K. 2015: How can GPs and community health services work more effectively together? British Journal of General Practice 65, 374-75.

Landers, S. and Levinson, M. 2016: Mounting evidence of the effectiveness and versatility of community health workers. American Journal of Public health 106, 591-92.

NHS England 2014: Five year forward view. London: NHS England.

Nolte, E. and Pitchforth, E. 2014: What is the evidence on the economic impacts of integrated care? Copenhagen: World Health Organization.

Penm, J., MacKinnon, N.J., Strakowski, S.M., Ying, J. and Doty, M.M. 2017: Minding the gap: factors associated with primary care coordination of adults in 11 countries. The Annals of Family Medicine 15, 113-19.

Pineault, R., Provost, S., Borgès Da Silva, R., Breton, M. and Levesque, J.F. 2016: Why is bigger not always better in primary health care practices? The role of mediating organizational factors. The Journal of Health Care Organization, Provision, and Financing 53, 0046958015626842.

Sheaff, R., Halliday, J., Øvretveit, J., Byng, R., Exworthy, M., Peckham, S. and Asthana, S. 2015: Integration and continuity of primary care: polyclinics and alternatives, an organisational analysis, Health Services and Delivery Research. Retrieved 12 April 2017 from http://dx.doi.org/ 10.3310/hsdr03350.

Smith, S.M., Wallace, E., O'Dowd, T. and Fortin, M. 2016: Interventions for improving outcomes in patients with multimorbidity in primary care and community settings. Cochrane Database of Systematic Reviews 18, CD006560.

Thompson, J. D. 2011: Organizations in action: social science bases of administrative theory. Volume 1 New Brunswick, NJ: Transaction Publishers.

van den Hombergh, P. and Campbell, S. 2013: Is 'practice size' the key to quality of care? British Journal of General Practice 63, 459-60. 